\title{
Libros de texto de la historia de Brasit: Entre sujetos, prácticas y métodos (Río de Janeiro, 1870-1920)
}

\author{
Textbooks of the history of Brazil: Between subjects, practices and methods \\ (Río de Janeiro, 1870-1920) \\ Alexandra Lima da Silva \\ Doctora en Educación por la Universidad del Estado de Río de Janeiro (UERJ / 2012). Profesora visitante \\ en la Universidad de Illinois con beca CAPES, profesora en la Facultad de Educación de la UERJ, \\ y profesora del Programa de Posgrado en Educación (ProPed / UERJ). \\ E-mail: alexandralima1075@gmail.com
}

Doi: https://doi.org/10.22267/rceilat.194445.23

\section{Resumen}

Este estudio intenta comprender qué cambió y qué se mantuvo igual en la producción de libros de texto de historia brasileña durante el crecimiento de la cultura alfabetizada y el público alfabetizado en la ciudad de Río de Janeiro, de 1870 a 1920, a través de libros de texto de historia brasileña. Intenta seguir las acciones de los involucrados en este proceso (autores, libreros, editores y maestros) en busca de sus motivaciones y de los diversos significados involucrados en las experiencias de vulgarización del conocimiento histórico a través de manuales de enseñanza. La expansión de la enseñanza debe entenderse como parte de las discusiones sobre las ideas de ciudadanía y deber cívico en Brasil, particularmente en la relación entre educación y formación ciudadana, defendida por muchos, donde los sujetos lucharon a través de varias estrategias.

Palabras clave: Libros de texto; Historia de Brasil; Alfabetización; Ciudadanía.

\begin{abstract}
This study attempts to understand what changed and what stayed the same in the production of Brazilian History textbooks during the growth of literate culture and literate audiences in the city of Rio de Janeiro, from 1870 to 1920, through Brazilian History textbooks. It attempts to follow the actions of those involved in this process -authors, booksellers, editors and teachers- in search of their motivations and of the various meanings involved in the experiences of the vulgarization of
\end{abstract}


historical knowledge through teaching manuals. The expansion of teaching must be understood as part of the discussions regarding the ideas of citizenship and civic duty in Brazil, particularly in the relation between education and citizen formation, defended by many, where subjects fought through various strategies.

Key words: Textbooks; History of Brazil; Literacy; Citizenship.

\section{Introducción}

En el ámbito de la historiografía de la educación, hay muchos caminos y abordajes para explorar el universo de los libros en sus múltiples matices y posibilidades. Específicamente en relación a los trabajos acerca de los libros didácticos de Historia, muchas son las perspectivas y corrientes teóricas que se proponen a investigarlos, en un proceso donde nuevos trabajos surgen diariamente, con importantes contribuciones para el debate. En esa producción, se destacan algunos trabajos que se acercan al objeto presentado en este artículo.

Circe Bittencourt analizó la construcción del saber escolar en libros de texto de Historia referentes al periodo de creación de las primeras escuelas públicas elementales y secundarias hasta los años iniciales de la República. Aludiendo a toda la producción nacional, su trabajo es una importante contribución, sobre todo por percibir el objeto en sus múltiples dimensiones, apuntando hacía las articulaciones entre Estado y mercado editorial y para la complejidad de los dominios que involucran el libro: mercadería/ instrumento de enseñanza/ transmisión de ideas y valores (Bittencourt, 1993). Recientemente, esta autora hizo un balance de las trayectorias de las investigaciones acerca de la producción didáctica, evidenciando un crecimiento de investigaciones acerca de la temática, indicando los distintos sitios institucionales en donde se producen las investigaciones (Bittencourt, 2011, p. 487). El trabajo de Arlete Gasparello acompañó la configuración de la cátedra escolar en la enseñanza institucional secundaria brasileña, tomando como foco del análisis el Colegio Pedro II y los programas de enseñanza de la historia nacional (Gasparello, 2002). A su vez, Giselle Baptista Teixeira analizó los libros de lectura para la primaria en el imperio, concibiendo el libro no solo como un vehículo de circulación de saberes determinados, sino también como forma de control y dominación de la población. La autora indica que muchos libros de texto de historia se utilizaban como libros de lectura en las escuelas imperiales (Teixeira, 2008). La disertación de maestría intitulada Enseñanza y mercado editorial de libros didácticos de Historia de Brasil -. Rio de Janeiro (1870 -1924,) analizó la expansión del mercado editorial en la ciudad de Rio de Janeiro, desde la publicación de obras de cuño didáctico dirigidas a la vulgarización del conocimiento histórico (Silva, 2008). 
Por otro lado, hay análisis específicos acerca de los autores de libros de texto de historia, como los que tratan de Rocha Pombo (Luchesi, 2004; Silva, 2012), João Ribeiro (Hansen, 2000; Melo, 1997), Joaquim Manuel de Macedo (Mattos, 1993), Maria Guilhermina Loureiro de Andrade (Chamon, 2008), Joaquim Maria de Lacerda (Freitas, 2007), entre tantos otros.

\section{Autores de libros de texto de Historia de Brasil}

¿Por qué escribir libros didácticos? ¿Cuáles son los significados de la escritura de los manuales para los autores? ¿Ser autor de un libro didáctico sería lo mismo para todos? Al acercarme a la trayectoria de algunos autores, aunque, en muchos casos, pertenecieran a círculos comunes, constaté que la escritura de libros didácticos de historia de Brasil no significaba lo mismo para todos. De este modo, se seleccionaron para este análisis solamente algunos autores, los más emblemáticos desde mi punto de vista, para demarcar tales diferencias, asentándose principalmente para los lugares sociales de ellos.

Silvio Romero nació en Sergipe en 1851, graduado en Derecho en la Facultad de Recife. Fue periodista combativo, con intensa actuación en la prensa, crítico literario, sociólogo, historiador. En 1880 se vuelve maestro en el Colegio Pedro II, después de un disputado concurso, al defender la tesis: "De la interpretación filosófica en la evolución de los factos humanos".
Dueño de vasta producción bibliográfica, y ya con notoriedad y prestigio en la corte, escribe un libro didáctico direccionado para las clases elementales (Romero, 1890).

Para tipos como Sílvio Romero, escribir libros representaba no solo la difusión de sus ideas hacia un público escolar, sino también un acercamiento al "pueblo", ya que defendía una alianza entre el "pueblo" y los "hombres de las letras" en Brasil. (Romero, 1898, p. 25). Para Sílvio Romero, la misión de los "hombres de las letras" del país era regenerar la nación, y también era su responsabilidad la formación intelectual y cultural del "pueblo", un modo de "sacarlo del retraso y de la ignorancia, integrándolo a la marcha de la civilización". (Mota, 2000, p. 18). Por eso defendía la militancia como "un desdoblamiento de su acción de escritor y profesor". (Mota, 2000, p. 18).

Al igual que Sílvio Romero, Felisberto Firmo de Oliveira Freire (18581916) nació en Sergipe. Licenciado en medicina, se dedicó a la política y a la historia, ejerció las actividades de médico, periodista, parlamentario y político (fue ministro en el Gobierno Floriano Peixoto). Socio del Instituto Histórico y Geográfico, y miembro de la Academia Sergipana de Letras, su libro didáctico Historia de Brasil se adoptó por el Consejo de Instrucción de la capital federal, para uso en las escuelas públicas, publicado por la Librería Clásica Alves en el año de 1896.

También dueño de una vasta producción bibliográfica y ejerciendo 
inumerables actividades, que incluían la medicina y la criminalística, Afrânio Peixoto (1876-1947) defendía, en su libro didáctico para las clases elementales, la necesidad de una "educación cívica” en la formación de una nación, la cual no podría constituirse sin la “educación del pueblo", pues: "Los pueblos ignorantes y por eso desconsiderados abdican de sí en los otros y se vuelcan hacía la servidumbre y el desaparecimiento". (Peixoto, 1916). Por eso, escribir libros sería invertir en el combate al retraso y a la falta de instrucción del pueblo. Para el autor, solamente por medio del conocimiento de los orígenes y tradiciones de un país, sería posible la superación de la ignorancia y el camino a seguir era uno solo: el "saber".

También licenciado en Derecho, Joaquín Maria de Lacerda (1838-1886), nació en Rio de Janeiro, fue miembro de la Arcadia Romana. También se dedicó a la educación y su libro Pequeña historia de Brasil para las clases elementales fue reeditado por 80 años, grande éxito de ventas (Blake, 1895, p. 195).

Las trayectorias que se analizaron hasta aquí tienen en común las experiencias compartidas por "hombres de letras”. ¿Pero, será que todos los autores de libros didácticos hacían parte de las instituciones y medios de prestigio obligatoriamente? ¿Serían todos ellos "hombres de letras"?

La ubicación de las informaciones acerca de otros autores de libros didácticos me permitió que ampliara aún más el abanico de significados de esta experiencia, que no era la misma para todos, en la medida que gran parte de la autoría de libros didácticos no era exclusividad de los sujetos que pertenecían a medios de influencia (como el medio político), y de prestigio, en instituciones como el Colegio Pedro II, Instituto Histórico y Geográfico Brasileño, Academia Brasileña de Letras, entre otras.

Muchos autores de libros didácticos se destacaron exactamente por la actuación en el magisterio.

João Ribeiro era autor de una larga producción de libros didácticos de historia de Brasil y de gramática. João Batista Ribeiro de Andrade Fernandes nació en Laranjeiras, Sergipe (1860). Vino a Rio de Janeiro a los 21 años, donde se hizo Bachiller en Ciencias Jurídicas y Sociales, en 1894. Actuó como periodista, escribiendo muchos artículos para la prensa, habiendo sido también editor del almanaque Garnier y crítico en el periódico El Imparcial. Sin embargo, en la actuación en el magisterio ganó más notoriedad, teniendo en cuenta su larga experiencia como maestro en escuelas privadas, públicas y catedrático del Gimnasio Nacional (Colegio Pedro II) en las cátedras de Historia de la Civilización y del Brasil, en función de lo que escribió aproximadamente 15 obras didácticas de Historia y gramática, y recibió muchos premios. (Gasparello, 2002, p. 220).

Por la trayectoria de João Ribeiro, escribir libros didácticos era parte y fruto de su renombrada experiencia 
como maestro de historia, lo que incluía elaborar programas de enseñanza para las escuelas, perfeccionar métodos de enseñanza y exposición, criticando y evaluando "buenos libros didácticos" en la prensa, como hizo muchas veces en el periódico $O$ Imparcial y en el Almanaque Garnier.

Así como João Ribeiro, otros autores de libros didácticos se destacaron como maestros en el Colegio Pedro II, de los cuales apunto Luís de Queirós Mattoso Maia y Joaquim Manuel de Macedo, los dos son licenciados en medicina y escribieron libros didácticos nombrados Lecciones de Historia de Brasil desde la experiencia en el magisterio.

A su vez, algunos autores se han destacado por sus formaciones religiosas, de los cuales apunto el Relicario Fernandes Joaquim Caetano Fernandes Pinheiro, quien nació en 1825, en Rio de Janeiro. Era profesor en el Seminario Episcopal de São José y, además, le han nombrado, en 1857, maestro de Retorica, Poética y Literatura Nacional en el Colegio Pedro II, donde se quedó hasta su fallecimiento en 1876. Su producción bibliográfica se constituyó en gran parte por libros didácticos, en función de su ejercicio en el magisterio ${ }^{1}$.

También había muchos autores que escribían libros didácticos como un complemento de la actividad de

1. Entre los cuales cito varias ediciones de Episodios de la historia patria, contados en la niñez, publicadas por la librería Garnier a partir de 1860. maestría en cursos preparatorios para exámenes, como lo hacían Raul VilaLobos (1862-1899) y Alfredo Moreira Pinto (1848-1903). (Blake, 1895, p. 103). El primero era "licenciado por el Consejo Superior de Instrucción Pública y habilitado a dar clases de todas las disciplinas del curso de preparación”, (Blake, 1895, p. 103) y el segundo, licenciado en Letras por el Colegio Pedro II, era "maestro de geografía e historia del curso preparatorio, adjunto a la escuela militar, en donde también da clases particularmente", habiendo escrito diversos compendios y libros cortos para facilitar los exámenes de instrucción pública (Blake, 1895, p. $60)$.

Existían también maestros de localidades alejadas de las "áreas nobles" de la ciudad de Rio de Janeiro, quienes muchas veces solicitaban auxilio a las instituciones públicas para financiar las impresiones de obras y materiales didácticos, con el riesgo de la solicitud ser o no aceptada:

Del Inspector General interino: Comunica que el maestro de la tercera Escuela de la Localidad de Santana pide autorización para desprender [...] hasta el monto de $300 \$$ con la impresión de mil ejemplares de las cartas del sistema ba-ca-fa-da (Segundo Directorio de Impresiones Autorizadas, Rio de Janeiro, 1875, p. 27).

Es importante observar que el comunicado ignora el nombre del maestro, lo que no ocurre al tratarse de un maestro de instituciones de renombre como el Colegio Pedro II. 
Además, verifiqué que la autoría de libros didácticos no era solo privilegio masculino, pues encontré libros didácticos escritos por mujeres, como Guilhermina de Azambuja Neves, que además de maestra, era propietaria del Colegio Azambuja Neves, y autora de libros didácticos.

Encontré también autoras de libros de texto de Historia, como Maria Emúlia Leal, quien publicó Pequeña historia sagrada para la niñez, obra premiada para la Instrucción Elemental, y también autora de Rudimentos de Historia Universal (Blake, 1895, p. 231), además de Maria Guilhermina Loureiro de Andrade, natural de Minas Gerais, autora del libro Resumen de la Historia de Brasil para el uso de las escuelas primarias, que se publicó en Boston, en 1888, y que también era propietaria del colegio para niñas en Rio de Janeiro. (Chamon, 2005).

Tal vez la cantidad de autoras sea más grande pues la cantidad de autoras mujeres que actuaban en el magisterio público era elevada, y creció significativamente a partir de la segunda mitad del siglo XIX. Si en 1871 representaban alrededor de $1 / 3$ del profesorado primario, en el final de los años 1880, se volvieran la parte más grande. (Schueler, 2002, p. 60.) Lo que es fruto de la lucha de las mujeres en el sentido de haber conquistado derechos y participación política. Autoras como Nísia Floresta utilizaban la literatura, la instrucción y la prensa para criticar la posición de la mujer en la sociedad, además reivindicaba la diseminación de la instrucción femenina. Si no se puede afirmar que fue la regla, tampoco se puede hacerlo como excepción. (Bernardes, 1988.)

En la investigación encontré huellas de un significativo y creciente número de mujeres que tenían cargos en la Instrucción Pública o como propietarias de establecimientos de enseñanza, volcados en gran medida hacía la instrucción femenina, conforme a lo aludido en este trabajo. Muchas también se dedicaron a la producción de obras didácticas de lectura y geografía y/o volcadas hacia la cuestión de la enseñanza.

Además, otro aspecto que también salta a los ojos en el análisis de los autores es el momento en que han nacido, una vez que no todos eran de mediados o finales del siglo XIX. Hubo casos de autores que han nacido a principios del siglo XIX, como José Maria Velho da Silva (1811) y Antonio Álvares Pereira Coruja (1806-1889).

Antonio Coruja nació en Porto Alegre, hijo de padres pobres, actuó para sostenerse como maestro de primeras letras y su primer empleo fue de maestro en una escuela pública, impartiendo clases particulares por la noche. También ocupó el cargo de contable en el IHGB, y en 1840, fundó su primera escuela, el Liceo Minerva. (Lazzari, 2004). Aparte de sus varios libros didácticos publicados, (Coruja, 1855; 1857; 1873; 1877; 1854.) actuó como presidente de la Sociedad Imperial Amante de la Instrucción, además de haber sido político. 
A partir de las primeras décadas del siglo XX el perfil del autor de libros de texto cambia, pues hay casos de autores "especializados" en este tipo de publicación. Era el caso de Mario da Veiga Cabral, cuya producción de obras didácticas es mucho más grande que las publicaciones de otros géneros, lo que tal vez evidencie que el sentido de escribir libros didácticos fuera más importante que para otros autores reconocidos como importantes hombres de las letras del país, como Afrânio Peixoto y Sílvio Romero.

Mario da Veiga Cabral vivió hasta 1969 y es autor de muchos libros didácticos de historia, geografía, coreografia y hasta de libros de lectura, para las clases elementales, con muchas reediciones. Escribió su primer libro didáctico muy joven, a los 21 años, y no ha parado. Muchos de sus libros alcanzaron las 30 ediciones, con millares de tirajes. En 1942, había publicado más de 22 títulos distintos de libros didácticos, de los cuales 5 estaban destinados a la enseñanza de Historia de Brasil (Cabral, 1942).

Para los autores como Mario da Veiga Cabral, escribir libros de texto parece haberse constituido como una profesión y no una "especialidad literaria" entre tantas. Su especialidad era exactamente esta, escribir libros didácticos, de ahí vino su renombre y proyección como maestro, y no lo contrario, como João Ribeiro, Luis Queirós de Mattoso Maia, y otros.

Así como la autoría de libros didácticos (y de los libros de texto de la historia de Brasil), no se limitaba solamente a los hombres o al "mundo de las letras", también escribir y publicar un libro didáctico no debería tener el mismo significado para todos.

En esta perspectiva, podemos vislumbrar la escritura del libro didáctico en un universo social de embates y disputas, en distintas instancias: políticas, sociales, de mercado, pues para muchos, publicar un libro era una ardua tarea, sea por las pocas "habilitaciones" del autor, quien muchas veces, no era un "especializado" en lo que escribía, sea por el poco tiempo disponible para escribir. También eran distintos los caminos y luchas para publicar un libro, tratándose de una primera obra de un autor todavía "anónimo" y con pocas referencias, el camino era arduo, ni todos lograban obtener el financiamiento del Directorio de Impresiones Autorizadas. Incluso, muchos autores pagaban por la primera publicación que salía de las impresoras de tipografías.

Quienes pertenecían al cuadro efectivo de instituciones públicas recibían una indemnización por el costeo de sus publicaciones de carácter didáctico:

Solicitud de crédito de 10:300\$, al Ministerio de la Justicia para indemnizar el lente del Gimnasio Nacional João Ribeiro, del gasto de la publicación de sus obras - Historia de Brasil e Historia de Occidente y de Grecia. (Anales de la Cámara de los Diputados, 1902, vol. 10, p. 48).

Es interesante observar como en estos casos los autores -los dos ya reconocidos y con actividades profe- 
sionales estables y bien remuneradasadelantaban los pagamientos de los costos con la edición y la impresión de libros didácticos y solamente después el gobierno federal les "indemnizaba".

La necesidad de ofrecer referencia vía cualificación de sus autores puede evaluarse por medio de la presentación de listas de premiaciones en concursos, exposiciones, en las indicaciones de las reediciones sucesivas de algunas obras, en la circulación en los principales periódicos de reseñas, en los catálogos, que llenaban páginas de libros didácticos a cada nueva edición. Estas eran las principales estrategias de divulgación de los libros e indicaban también los espacios institucionales que servían al reconocimiento social de un buen autor de libros didácticos. Podemos evidenciar la preocupación por la distinción obtenida por los autores en la demarcación de límites entre la autoría de libros y actuación en el magisterio, una vez que no era una realidad común a todos los docentes.

La escritura de libros didácticos evidenció, en cierta medida, el espacio que sus autores ocupaban en este circuito. Este espacio, a mi ver, requería negociación y un juego de prestigio y distinción social, una vez que lo que permitía que un autor publicara libros en "grandes editoriales" era justo su "currículum", sus actividades y "status", lo que garantizaba cierta credibilidad, garantizando una posibilidad más grande de aceptación frente al público y la crítica. El esfuerzo en demarcar los círculos de los autores puede interpre- tarse más como un indicio de que ni todo autor de libro didáctico adivina los círculos y los medios de influencia.

Acerca de esa necesidad de "referencias" del autor, se puede notar un gran destaque de las tapas o contratapas al origen del autor, su experiencia en el magisterio, sobre todo en los colegios Pedro II, Escuela Normal o Escuela Militar o la propiedad de escuelas. También se ponía atención a otras publicaciones del autor, así como a las instituciones de actuación en investigación, como IGBH, Biblioteca Nacional, Archivo Nacional, entre otras instituciones que se consideraban padrón en la época. La experiencia en el magisterio también importaba para algunas editoriales.

Aunque muchos autores alegaran producir sus manuales a partir de los pedidos o de las necesidades surgidas en clase, no todos los maestros tuvieron su material publicado. La práctica de autoría de libros didácticos no se amplió hacia todas las realidades escolares, pues muchas veces los libros didácticos se volcaban al propio proceso de formación y auxilio de los maestros en clase.

Así, supongo que los usos y procesos de elaboración de los libros destinados a la enseñanza cambiaron a lo largo del tiempo, en función de las transformaciones en las relaciones sociales que los producían. Escribir libros didácticos, por lo que mostró el análisis de la trayectoria de algunos autores, hizo parte de un proceso más amplio de transformaciones en la edu- 
cación y en la cultura letrada. Ser autor de un libro didáctico no era lo mismo para todos: para un profesor de un municipio alejado, tenía un sentido, para un licenciado actuante en el centro urbano, otro, lo que era distinto para una profesora de primaria.

Para algunos, escribir libros didácticos resultaba de la distinción social, lo que era una actividad profesional más, ejercida para prestigio y proyección más grandes, mientras que, para otros, era uno de los instrumentos de lucha para mejorar la enseñanza, ampliar la instrucción, aún más, una fuente de renta, aparte de representar alguna mejoría en las condiciones del propio trabajo y de vida.

\section{Ciudad letrada: editores y libreros}

A partir del análisis de los anuncios de escuelas particulares en el Almanak Laemmert en la década de 1880, observé indicios de la existencia de contacto cercano entre los dueños de colegios con algunas librerías que también eran editoriales. Tales indicios reforzaron aún más la idea de una articulación entre enseñanza/mercado editorial didáctico, lo que me hizo, a su vez, reunir pistas acerca de sus propietarios y acerca de un "negocio" en plena expansión en la ciudad - la edición y venta de libros.

Los "negociantes de libros" componían un painel de distintas nacionalidades en la ciudad de Rio de Janeiro, a finales del siglo XIX y comienzos del XX. Eran portugueses, como Nicolau
Alves, de la Librería Clásica; Luiz Ernesto Martin, de la Librería Portuguesa; franceses como Garnier y Villeneuve; alemanes, J.H. Auller, de la Librería Alemana; más allá de brasileños, como Pedro da Silva Quaresma, de la Librería Quaresma, entre otras, que componían un grupo heterogéneo, mostrando la existencia de un comercio librero intenso que se ubicaba en las principales calles del centro de la ciudad, con destaque para la famosa Calle Ouvidor y adyacencias.

Pero ¿quiénes eran estos "negociantes de libros"? ¿Qué explicaban estos expresivos números? ¿Por qué aventurarse en el ramo de los libros si "el pueblo no leía”? ¿Cuáles los retornos sociales y ganancias financieras involucradas en este "negocio"?

Los estudios acerca del mercado editorial en Brasil apuntan a Rio de Janeiro como el punto de partida de la expansión editorial en el país. Aunque algunos investigadores sigan enfatizando el predominio de solamente dos libreros-editores al largo de todo el siglo XIX, los Hermanos Laemmert y los Garnier, sin considerar los significados de la existencia de otros libreros y editores también importantes en aquel periodo, no es más posible seguir menospreciando las indicaciones acerca del número creciente de editores y comerciantes de libros en la ciudad. (Hallewell, 1985.) Al acompañar los anuncios del Almanak Laemmert, se hizo posible rastrear los establecimientos de venta y publicación de libros en Rio de Janeiro, con variadas ofertas de 
mercaderías, productos y servicios. Entre 1870-1900, se constató la existencia de por lo menos 121 empresas que se dedicaban al comercio librero. (El Far, 2004.)

Si ponemos atención a las direcciones de las librerías: Calle São José, Calle de la Quitanda, Calle del Sabão, Calle Uruguaiana, Calle Gonçalves Dias, Calle del Rosário, Calle de São Pedro, Calle de los Ourives, Calle de la Alfândega, Calle Sete de Setembro, Calle Santo Amaro, Calle de la Asamblea, Calle de la Passagem, podemos percibir una disposición espacial más allá de la afamada Calle del Ouvidor. Quienes se establecían en esta calle parecían tener un capital más grande o era la dirección de aquellos que llevaban más tiempo en el mercado. Podemos decir que las casas editoriales más "lujosas" disfrutaban de la Calle del Ouvidor, pero solamente después de haber migrado mucho por otras calles de la ciudad.

Los alrededores estaban llenos de concurrencia que cambiaba frecuentemente de dirección para ubicarse mejor en la conquista de nuevos públicos consumidores, divulgando el "nombre" junto al mercado, como aprendemos al acompañar los anuncios del Alamanak Laemmert. El librero portugués Nicolau A. Alves, propietario de la Librería Clásica, por ejemplo, se instaló, en 1860, en la Calle de los Latoeiros, 54; en 1870, en la Calle de Gonçalves Dias, 26; en 1889, amplió su filial en la Calle Gonçalves Dias, que ocupaba los números 46 y 28, además de la Ladera del Senado, 25 A. Conviene poner atención en que esta librería se especializó en libros didácticos y colegiales.

Otra especificidad de la producción editorial del periodo era la división en el proceso de producción, era importante demarcar distintas funciones, entre las cuales hay las de los tipógrafos, encuadernadores, editores, libreros. Muchos eran solo "libreros", eso es, dueños de librerías involucrados con el comercio de libros; algunos, "libreros-editores", que trabajaban también con la producción y difusión del libro, y asumían el rol intermediario entre el autor y el público, más allá de la venta de libros; y aún existían los que vendían, editaban e imprimían libros simultáneamente, al concentrar básicamente casi todo el proceso de producción (Lima, 1985, p. 27).

Conforme el Catálogo del Museo Escolar Nacional de 1885, las editoriales Larmmert Garnier y Francisco Alves eran responsables por más del $44 \%$ de toda la producción brasileña de libros escolares. Sin embargo ¿a quién cabría el 56\% de la producción didáctica? Por medio del rastreo y análisis de libros didácticos de historia de Brasil se puede observar la existencia de otros libreros, editores y tipografías que se dedicaron a la publicación e impresión de manuales de historia nacional. Más allá de las tres mencionadas, encontré libros didácticos publicados por otras editoriales, como: Domingos Gomes Brandão, Jacinto Cruz Coutinho, Jacinto Ribeiro Editor, Tipografía de Gueffier E. C, A. J. Castilho, Tipografía de M. Gomes Ribeiro, Librería Quaresma, J. 
G. de Azevedo Editor, además de las tipografías: Tip. Esperança, Tip. do Figaro, Tipografía de M. Gomes Ribeiro, Tip. brasiliense de M. G. Ribeiro, Tip. Aldina, entre otras.

\section{Libros didácticos: ¿un producto de las masas?}

¿Qué explica la inversión del Estado, de autores, de libreros, de editores, en la publicación de ediciones de libros didácticos nacionales? En fin, ¿cómo el libro didáctico se ha vuelto "un producto de masas", producido en gran escala?

En el periodo de 1870 hacia 1924, hubo muchos cambios en el mercado de libros escolares, que se convirtieron de objeto raro, caro y para pocos, en "libros para todos los gustos e bolsos", "accesibles al público en general", vendidos "a precios módicos", que se podían encontrar en muchos sitios, con lenguaje claro y accesible a muchos gustos y "sentidos". Al analizar los libros didácticos, uno se da cuenta de la ampliación de su público. Inicialmente, se volcaban hacia los propios maestros y alumnos de la secundaria, con destaque a los "alumnos del Imperial Colegio Pedro II” y colegios militares. A partir de la segunda mitad del siglo XIX, se consideran otros públicos, como las escuelas particulares, las públicas, escuelas normales, y principalmente, las clases primarias y elementales, al acompañar las inversiones en la enseñanza primaria y en la enseñanza para adultos. Se han observado muchos autores que empezaron con la escritura de libros didácticos para la secundaria, y han pasado a dedicarse también, posteriormente, a la escritura de libros para las clases elementales. Nombres como João Ribeiro, Joaquim Manuel de Macedo, Rocha Pombo, Afrânio Peixoto, Sylvio Romero y Mario da Veiga Cabral fueron algunos de los que escribieron para las clases elementales.

A lo largo de todo el periodo analizado, es posible acompañar muchos cambios en la producción del libro didáctico en sus aspectos gráficos y técnicos, tales como formato, lenguaje, lo que se reflejó en la economía en la producción, en la disminución de los precios, en el incremento del número de tirajes y de ventas. La presencia de ilustraciones en los libros didácticos también se volvió frecuente, pese a las resistencias de algunos editores, debido a los costos que se generaron por el uso de ilustraciones.

Innumerables aspectos contribuyeron para la ampliación y diversificación del público lector de libros didácticos. Muchos de los cuales ya han sido puntuados y analizados en esta investigación. En este sentido, conviene poner atención para los aspectos del precio y tiraje de los libros, lo que nos ayuda a dimensionar las posibilidades de difusión de ellos.

Según Circe Bittencourt, los libros (novelas, cuentos, etc) publicados en Brasil, poseían tiraje mediana de mil ejemplares. Sin embargo, los libros didácticos tenían tirajes más grandes, 
y muchas reediciones: "Los manuales destinados a las escuelas primarias, en sus primeras reediciones oscilaban entre 2.000 y 4.000 ejemplares y los de receptividad más grande lograron constantes reediciones, a veces anuales, que alcanzaban los 6.000 ejemplares" (Bittencourt, 1993, p. 108). El libro de Joaquim Manuel de Macedo, Lecciones de Historia de Brasil, para uso de las escuelas, por ejemplo, tuvo sus dos primeras ediciones por la Casa de Domingos José Gomes Brandão con más o menos seis mil ejemplares cada una, sin mencionar las ediciones posteriores hechas por la editorial Garnier.

Sin embargo, se han ubicado muchos libros didácticos con hasta diez mil ejemplares por edición, con muchas reediciones durante años y utilizados por muchas generaciones:

Esta segunda edición de la Pequeña Historia de Brasil por preguntas y respuestas, el autor la publica bajo la más grata satisfacción que le generó la noticia de haber su obrita merecido el insigne honor de haber sido aprobada por el Consejo Superior de la Instrucción Pública. También fue animado a emprenderlo por el lisonjero acogimiento que obtuvo junto a los Señores Maestros y Directores de los Colegios, a quienes se debe el gran resultado de haberse agotado en pocos años la primera edición, que fue de diez mil ejemplares ${ }^{2}$.

2. Nota a la segunda edición en 1880 , de Pequeña Historia de Brasil por preguntas y respuestas para uso de la infancia brasileña, de Joaquim Maria de Lacerda. Grifos míos.
El Compendio de historia de Brasil de Mario da Veiga Cabral alcanzaba su $6^{\text {a }}$ edición en 1929 con una marca de sesenta mil ejemplares y una media de diez mil ejemplares por tiraje desde su primer edición en 1920. Todavía en relación a las obras de este autor, en 1924 algunas reediciones de sus libros alcanzaban marcas de diez mil tirajes. Este fue el caso del Compendio de Coreografía de Brasil, que alcanzaba con la séptima edición en 1924, el $100^{\circ}$ millar. Sus otros libros didácticos también vendían bien: la $3^{\mathrm{a}}$ edición del Compendio de historia de Brasil ilustrada con ciento y veinte ocho grabaduras, atingía el $30^{\circ}$ millar; Nuestra Patria, en su $2^{\mathrm{a}}$ edición, el $10^{\circ}$ millar; y la Pequeña historia de Brasil, el $5^{\circ}$ millar. Todos publicados por la librería de Jacintho Ribeiro dos Santos Editor hasta 1924:

Obras del mismo autor:

Historia de Brasil, $17^{\mathrm{a}}$ edición con más de 180 grabaduras, $170^{\circ}$ millar.

Nuestra Patria, $14^{\mathrm{a}}$ edición, $140^{\circ} \mathrm{mi}-$ llar, oficialmente adoptada en DF, ES, RJ, SP, BA, CE, PE.

Primer libro de lectura, un volumen ilustrado, $23^{\mathrm{a}}$ edición, $230^{\circ}$ millar.

Según libro de lectura, $16^{\mathrm{a}}$ edición, $160^{\circ}$ millar- agotado

Tercer libro de lectura, $16^{\text {a }}$ edición, $160^{\circ}$ millar- agotado

Cuarto libro de lectura, $5^{\mathrm{a}}$ edición, $50^{\circ}$ millar (Cabral, 1924).

Al acompañar las reediciones de los libros didácticos, se observa que los intervalos entre una reedición y otra eran pequeños, el tiempo de agotar la 
edición anterior, alrededor de un año. En términos de ejemplificación, el libro Pequeña historia de Brasil tuvo desde la primera edición, en 1923, hasta la última, en 1951, un total de diecinueve ediciones.

Aparte del elevado número de tirajes de los libros didácticos, había una atención especial hacia el tamaño y los precios en este tipo de libro. Sobre todo con la ampliación de la red escolar elemental y formal, los libros didácticos y las cartillas para el "pueblo" se anunciaban "a precios módicos", con la preocupación de volverlos accesibles a todos los bolsillos y clases.

Sin embargo, ¿quién invertía en los "libros para el pueblo"? ¿Por qué? ¿Qué volvería un libro "accesible a todos los bolsillos"?

Los precios de los libros en este periodo parecían variables en cada editorial, en función del tipo de libro y del público al que se destinaban. En facto los libros didácticos y populares eran más accesibles que otros en la época. $\mathrm{Al}$ analizar el costo de vida en Rio de Janeiro a finales del siglo XIX tenemos que un maestro de la primaria recibía alrededor de 150\$000 de sueldo; un sirviente, 60\$000; un médico, cerca de 300\$000 (Damazio, 1996, p. 48.) Con esto, comprar libros didácticos no era una realidad incompatible con los distintos sueldos de la época, si tenemos en cuenta que existían libros que costaban menos que $1 \$ 000$, valor sesenta veces más pequeño que el sueldo medio de un sirviente, por ejemplo. En relación a las primeras décadas del siglo XX, los precios crecieron, pero también crecieron los valores de los sueldos. El resumen del catálogo de la Librería Francisco Alves traía los precios de algunos libros didácticos: el libro de composición de Olavo Bilac y Manuel Bomfim costaba $4 \$ 000$; el Examen de Admisión para los gimnasios Prontuário de las materias exigidas para el examen de admisión en el colegio Pedro II, por João Ribeiro y Raja Gabaglia, 3\$000; Proverbios populares, por D Alexina de Magalhães, $2 \$ 000$; Canciones de los niños y del Pueblo (edición ilustrada y con las canciones), por D. Alexina de Magalhães y Pinto, 4\$000 (Lacerda, 1919, reverso de la página).

Otro factor que contribuyó para la ampliación del público lector de libros didácticos fueron los cambios en los aspectos gráficos y técnicas. Los tamaños de los libros didácticos deberían volverlos "manuales", en el sentido de una lectura más amena y también de fácil transporte del lector. Atentos a la necesidad de leer en distintos sitios, facilitar el manoseo de los libros y disminuir los costos, los editores cuidaban de producir libros en formatos más pequeños, "in- $4^{\text {o" }} \mathrm{e}$ "in- $5^{\circ}$ ", encuadernados o en encuadernaciones rusticas. El formato in $-4^{\circ}$ equivaldría a una hoja tamaño oficio plegada dos veces, componiendo un cuaderno más pequeño, de ocho páginas, por otro lado el in- $8^{\circ}$ era aún más pequeño, componiendo un cuaderno de 16 páginas, a partir de tres pliegues de una misma hoja (El Far, 2006, p. 32.) Tales libros, en formatos pequeños, baratos y de lectura fácil, 
circulaban por la ciudad, sea por las librerías, sea en las ventas que los mercadores ambulantes promovían (Rio, 1987, p. 10).

Por las evidencias que se reunieron, se puede observar que los precios variaban entre $2 \$ 000$ y $8 \$ 000$, siendo decisivo en el precio del libro, el público a que se destinaba, así como la cualidad del material que se utilizó, el formato y los recursos gráficos (papel, tamaño, numero de edición, uso de imágenes, grabaduras, fotografías). Al acompañar el Almanak Laemmert, se nota la existencia de litografías y estamparías en la ciudad: "Laemmert \& C (...). Con litografía a vapor artística y comercial, provee todos los trabajos litográficos con la brevedad más grande y perfección, y hechos los mapas por medio de procesos fotográficos, a precios muy cómodos"(Almanak Administrativo, Mercantil e Industrial para el año de 1889, p. 1384). No es raro, con esto, el creciente uso de fotografías y grabaduras en libros didácticos.

Si inicialmente, había la necesidad de limitar el uso de ilustraciones en un libro didáctico, para volverlo más accesible y barato, se nota que, a principios del siglo XX, este cuadro cambia, pues había un uso abundante de imágenes, grabaduras y fotografías. Esto se debe al bajo costo del proceso de producción, y al uso de nuevas técnicas de impresión. Con esto, muchos libros que no disponían de ilustraciones en las primeras ediciones, empezaron a disponer de este recurso en ediciones posteriores, como aprehendimos en el libro Pequeña Historia de Brasil, de Dr. Joaquim Maria de Lacerda, que no presentaba ilustraciones en la segunda edición en 1888, lo que cambia en la edición de 1888, publicada "con muchas grabaduras y retratos notables" (Blake, 1895, p. 193).

En este sentido, se evidencia el uso más grande de cuadros y pinturas históricas en los libros didácticos de historia y fotografías en blanco y negro. Tal inversión demuestra una preocupación en dar "aires" de actualidad y cualidad a este tipo de libro, además de facilitar la lectura y comprensión de lo que se trasmitía, por medio de la supresión de parte de los textos o reducción del tamaño de otros.

Además, la añadidura de imágenes se encuentra con la idea de ampliación de lectores, pues las imágenes eran un atractivo más, más allá de su "carácter facilitador" y "explicativo". El uso de imágenes fue más abundante en los libros volcados a la instrucción de los niños y a las clases primarias, pero muchos libros para las clases secundarias también empezaron a disponer de este recurso.

Hasta mediados del siglo XIX la elaboración de libros didácticos se relacionaba mucho con las instituciones como el IHGB y el Colegio Pedro II, con la intención de producir manuales para la enseñanza de la historia de Brasil que sustituyeran las traducciones de manuales didácticos de la historia de Brasil hechos por autores extranjeros $y$, muchas veces, impresos en tipografías extranjeras. Hasta este momento predo- 
minaban los libros escritos por maestros del Colegio Pedro II, conectados al IHGB, todavía volcados al público más restricto, tales como profesorado, alumnos de la instrucción secundaria, con énfasis en los alumnos del propio Colegio Pedro II y un público general, adulto, interesado en conocer la historia patria. En este sentido, hay algunos libros publicados por editoriales como Laemmert y Garnier, muy conectadas al poder institucional.

Con esto, tenemos la comprensión de que el libro didáctico no "nació" masificado. La preocupación inicial era con un público específico, que ya dominaba las primeras letras. De ahí la densidad y volumen de las obras. Sin embargo, con la expansión de la red escolar, la producción didáctica se amplía más allá del Colegio Pedro II y más allá de las editoriales "consagradas" que publicaban solo los "grandes nombres". El público se diversifica, así como hay un aumento en la oferta de libros y un número más grande de involucrados en la producción didáctica. Hay una creciente ampliación en el mercado librero, con la presencia de fabricantes de papel, mercaderes ambulantes de libros, tipógrafos, libreros, encuadernadores, talleres de litografía y estampas, entre otros.

En lo que se refiere al "público objetivo", en el periodo entre 1870-1924, los direccionamientos de los libros didácticos se amplían de la secundaria al modelo para niños de otros públicos. Así, hay libros didácticos hechos para distintos públicos (maestros, alumnos, "pueblo") y niveles de instrucción: elemental, secundaria y superior (preparatorios para exámenes para las escuelas superiores), al adecuarse las temáticas y cuestiones y el tratamiento dado a ellos de acuerdo con los grados de profundización diferenciados, lenguajes, y hasta metodologías diferenciadas.

El libro escrito para mozas de la Escuela Normal demuestra que este público necesitaría, en las concepciones de aquel período, de nociones esenciales para la instrucción de los niños, sin la necesidad de una profundización más honda en las cuestiones, por medio de otros compendios, siendo algo no "muy elaborado", dispensado investigación elaborada. Lo que es distinto de la composición de libros para otros públicos, que necesitarían más atención a la investigación documental. Ya los libros para el público infantil y "popular" evidenciarían innumerables especificidades, como el formato y el tamaño reducidos, el uso de imágenes, el lenguaje más simple. Es interesante observar que los libros escritos para los "hombres simples del pueblo" eran los mismos dedicados a los niños, lo que indica que los métodos y lenguajes que se utilizaban para ambos podían ser los mismos o semejantes a pesar de las distinciones de estos públicos en experiencias y necesidades.

La preocupación en bajar cada vez más el costo de la producción se debe a la posibilidad de disminuir los precios para el comprador, aumentando el número de tirajes, añadiendo imágenes, direccionando el lenguaje hacia 
el público. Así como los periódicos tenían gran capacidad de penetración en las "camadas no letradas de la población” (Mello, 2007, p. 80), los libros didácticos se volcaban cada vez más hacia la población semi-letrada y poco instruida, alcanzando en algunos casos el mismo precio de ejemplares de periódicos, con tirajes mucho más largas que estos. La Revista Ilustrada, por ejemplo, tenía una tiraje de cuatro mil ejemplares, mientras muchas ediciones de libros didácticos alcanzaban los diez mil. De este modo, tener libros didácticos que alcanzaban estos números en reediciones, ayuda a entender los $61 \%$ de personas alfabetizadas en la ciudad de Rio de Janeiro a principios de la década de 1920. Con esto, se comprende porque muchos veían en el comercio de libros didácticos más que un negocio lucrativo, involucrando sujetos e intereses distintos.

Si escribir libros didácticos traía ganancias financieras y más seguridad que otros géneros para algunos autores, para los editores, invertir en "libros populares", "costo muy bajo", "al alcance de todos los bolsillos", objetivaba no solo atingir distintos públicos consumidores, pero atingir y formar "nuevos" lectores. Para los "negociantes de los libros", apostar en la "educación del pueblo", ofreciendo libros accesibles no solamente en precios pero también en locales de compra, en divulgación, en métodos de exposición, en lenguaje, era invertir en la propia supervivencia, una vez que sin lectores no era posible vender libros y seguir publicando. Entre 1870-1924 a partir de una red de comunicación social compleja e interdependiente, en un movimiento de luchas y embates entre los distintos sujetos involucrados, los editores se destacaron como los articuladores alrededor de la cultura letrada en la ciudad de Rio de Janeiro. Tales articulaciones no se limitaron a los "hombres de letras”, también la componían comerciantes, tipógrafos, autores, maestros, alumnos, entre otros.

En suma, la afirmación acerca de la transformación del libro didáctico en "producto de las masas" se basa en la observación de muchas variables: el crecimiento del número de tirajes de los libros, que era más grande en relación a otros géneros, las reediciones frecuentes, además del bajo costo de los precios de los libros didácticos y la diversificación del público-objetivo.

\section{Libros didácticos: lenguaje, métodos, aprendizajes}

Uno de los aspectos más característicos de "un buen" libro didáctico eran la metodología y el lenguaje adecuados a los alumnos. Los anuncios de los libros didácticos evidencian estas preocupaciones, sobre todo en la capacidad del autor en la adecuación metodológica de los contenidos a los públicos a los cuales se dirigen, con énfasis en el estilo de la narrativa, que debería redactarse "con orden, claridad y precisión”, no se debía "entrar por un estudio profundizado y substancial" al 
que "principian y no pueden todavía entrar por un estudio profundizado"3.

En elegante y bien impreso librito de 121 hojas, los autores de los 'Cuadros' compendiaron, dándoles la exposición simple de un librito didácticamente útil, los principales factos de la Historia del Brasil, que interesaron más de cerca a la inauguración de los discentes de las primeras clases. (Periódico de Brasil, 4-3-1918).

Un buen libro didáctico sería aquel que se acerca al lector, "al satisfacer la curiosidad de los chicos”, adecuándose al universo vocabular de la "puericia”, "sob la agradable forma de conversación de una madre con sus hijos, a través de lo que el autor inicia los lectores en la Historia del Brasil (...)”4. El libro debe ayudar el maestro en la enseñanza de la historia nacional, "Por la novedad y excelencia del método y la forma amena que supo darle su autor, creemos que el presente librito será en todos los colegas adoptados para la enseñanza de la historia nacional" (Idem). Un buen libro didáctico debe presentar los contenidos "en el orden de los tiempos, en un lenguaje ameno, fluente, y sobre todo, comprensible a las verdes inteligencias de sus lectores" ${ }^{5}$. El co-

3. Anuncio de "Lecciones de historia de Brasil para los alumnos del Imperial Colegio de Pedro II", en el Catálogo de la Librería Garnier, 1877.

4. Anuncio en el Catálogo de la Librería Garnier para el libro de MENEZES (Estácio de Sá)- Historia de Brasil contada a los niños.

5. Fernandes Pinheiro (Cônego Dr. J. C). Episodios de Historia patria. Anuncio en el Catálogo Garnier, 1877. nocimiento de la historia patria es necesario, el libro didáctico debe ser un vehículo difusor por todo el país. De este modo, observamos la "didáctica" de algunos autores.

La obra de Joaquim Manuel de Macedo Lecciones de Historia de Brasil para los alumnos del Imperial Colegio Pedro II, tenía como característica la organización y sistematización de los contenidos, sea en la distribución de los mismos en lecciones, clases, sea a través de cuadros, resúmenes y explicaciones, una vez que "Números y cuadros explicativos, trazados con espíritu de método y clareza perfecta, resumen las lecciones y añaden cada vez más el merecimiento de un libro ya por tantas calidades recomendables" ${ }^{\text {. }}$

La idea de resumir cada lección en cuadros ayudaba en la fijación de los puntos más importantes de la lección estudiada. A su vez, los esquemas sistematizaban las acciones y los hechos de los “personajes" importantes de la Historia.

Las explicaciones seguían la forma de artículos de diccionario, al definir acciones, sitios, pueblos, entre otros, de modo a elucidar los puntos de probables dudas en los estudiantes de historia. Al fin, cada lección presentaba ejercicios en forma de preguntas para verificar la fijación del contenido

6. Anuncio de "Lecciones de historia de Brasil para los alumnos del Imperial Colegio de Pedro II", en el Catálogo de la Librería Garnier, 1877. 
trasmitido, a través de la fórmula de las preguntas.

Otra metodología utilizada en los libros era la composición del libro en preguntas y respuestas en su totalidad, como hizo Joaquim Maria de Lacerda en su libro fechado en 1880.

Maria Guilhermina Loureiro de Andrade no presenta su libro estructurado alrededor de preguntas y respuestas, como hizo Joaquim Lacerda. Sin embargo, al final de cada lección traía preguntas para memorizar el contenido.

Las preocupaciones con la calidad de los libros didácticos no responden solamente a la adecuación del lenguaje, al tamaño del libro, a los métodos de exposición. Los cambios gráficos en el proceso de producción de los libros también deben tomarse en cuenta. El uso de grabaduras, por ejemplo, era reducido por los editores para no encarecer mucho el producto:

La Historia de Brasil del Señor Veiga Cabral, llena una gran omisión de los programas de nuestros establecimientos de enseñanza. El autor de esa obra deseaba publicarla con todo el cariño, al ilustrar sus personajes principales, con fotografías históricas, con lo que tal vez no haya estado de acuerdo el editor debido a las espesas que acarrearía este trabajo ${ }^{7}$.

Sin embargo, a partir de comienzos del siglo XX el uso de grabaduras

7. Gaceta de noticias, 4-5-1920. se vuelve más frecuente en los libros didácticos, y hace parte de las características de un "buen libro didáctico". Algunos libros que tuvieron pocas o ninguna grabadura en las primeras ediciones, empezaron a disfrutar más de esta “innovación”. . Tal preocupación se justifica por la necesidad de alcanzar públicos más grandes, más allá de los distintos usos y sentidos de las imágenes por los libros didácticos. Tales imágenes eran de distintos grupos: mapas, grabaduras de objetos, reproducción de fotografías y dibujos de los "personajes célebres de nuestra historia”, paisajes, además de las imágenes de viajeros y pinturas históricas.

El libro Nuestra patria. Narración de los factos de la Historia de Brasil a través de su evolución con muchas grabaduras explicativas, de autoría de Rocha Pombo es uno de los que se ha destacado por el uso de imágenes, así como por el lenguaje, una narrativa en formato de conversación ${ }^{9}$. Este libro tiene muchas características interesantes. Su formato pequeño, así como la gran parte de los libros con destinación

8. Fue lo que pasó con la Pequeña Historia de Brasil por preguntas y respuestas, de Joaquim Maria de Lacerda. Mientras la edición de 1880 no presentaba grabaduras, la edición de 1888, presenta "muchas grabaduras y retratos de hombres notables". Lo mismo pasó con la cuarta edición de Puntos de Historia de Brasil, de Raul Villa-Lobos, que en la cuarta edición, salida a finales del siglo XIX era "correcta, ampliada y ornada con 21 grabaduras” (BLAKE, 1895, p. 193-195)

9. La edición utilizada en este trabajo fue el número 60. 
a la enseñanza primaria, teniendo al total, 160 hojas, con textos pequeños y permeados por muchas grabaduras, que hacen parte del cuerpo del texto, auxiliando las exposiciones del autor. El lenguaje simple, a través del cual el autor parece intentar establecer una conversación o diálogo con el lector, una vez que en las palabras del propio autor. "Este librito está hecho para la inteligencia de los niños y de los hombres simples del pueblo"10. Para este autor la imagen es un refuerzo para la explicación del texto, al dar "veracidad" más grande o aún el convencimiento por el uso de "pruebas" comprensibles al lector, ayudándole en la explicación y en la visualización "de los hechos" históricos. Más allá de escribir pensando en distintos públicos, Nuestra Patria tuvo amplia circulación por el territorio nacional, como se puede comprobar en las indicaciones de la tapa del librito: "Aprobada oficialmente en los Estados de São Paulo, Rio de Janeiro, Santa Catarina, Sergipe, Maranhão y adoptada en la enseñanza de esos Estados y de Paraná, Bahia y Rio Grande do Norte”. Se publicó de 1917 hasta 1970, todas las ediciones contenían muchas imágenes.

El libro de Rocha Pombo se distingue de los demás libros didácticos analizados aquí por traer los modos de vida en la colonia y en el Imperio, principalmente indígenas y esclavos. Sin embargo, en las imágenes acerca de estas "razas", ponía énfasis en el

10. Prefacio a la $60^{\mathrm{a}}$ edición. carácter poco "civilizado" de estas en relación al europeo. En la imagen y el texto arriba, por ejemplo, los indios figuran como "salvajes", pues resuelven todo en la guerra, al contrario del "hombre civilizado" que utiliza la razón en detrimento de la fuerza.

El otro libro de Rocha Pombo, Historia de Brasil, también trae un interesante painel de D Pedro II, distinto de las imágenes frecuentes en los libros didácticos, trayendo el emperador siempre anciano o siempre un niño de 5 años. Ver figura 1.

Figura 1. D. Pedro II

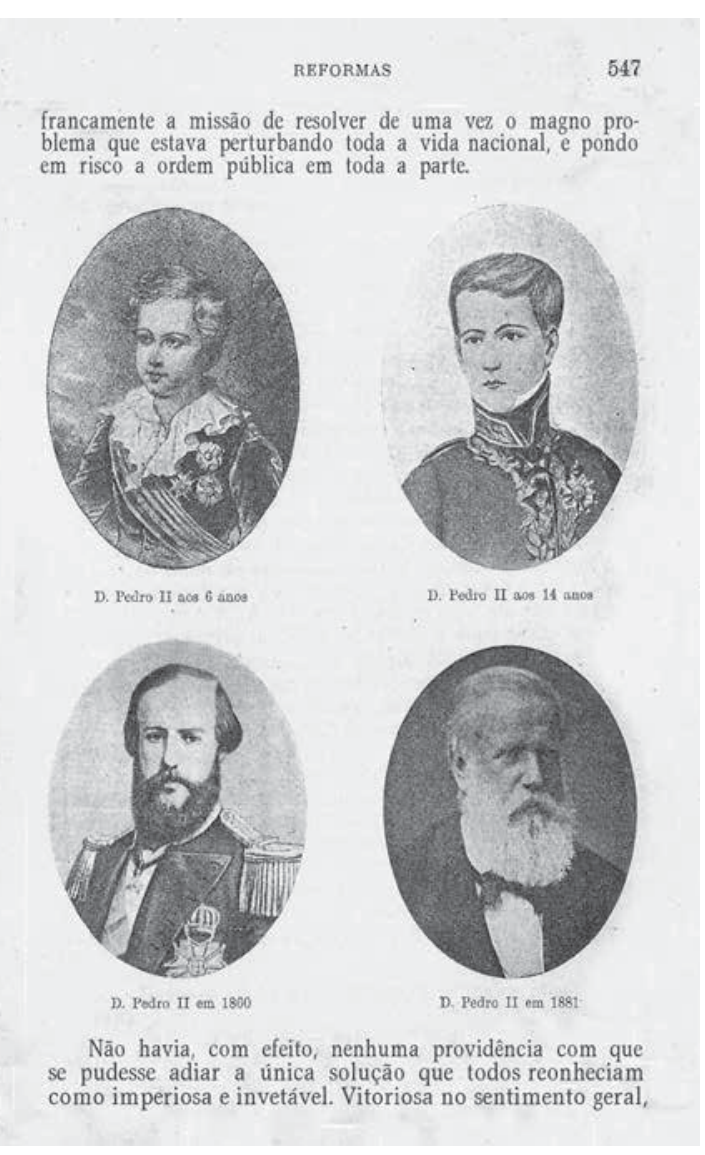

(Rocha Pombo. Historia de Brasil. 1948, p. 547). 
La Compañía Melhoramentos, que también publicó los otros dos libros de Historia de Brasil de Rocha Pombo, tendría total libertad para cambiar la composición del libro en sus varios aspectos, como formato, ilustraciones, grafía, entre otros, lo que nos ayuda a comprender las sucesivas reediciones que tal obra tuvo por esta editorial: "Autorizo la Compañía Melhoramentos de São Paulo a usar en la composición de los compendios que le haya escrito y estoy escribiéndole, la grafía que le convendrá".

Araripe Júnior al analizar la obra de João Ribeiro, afirma que trae un "método de enseñanza que se asocia al histórico", dos habilidades únicas del autor reflejadas en este trabajo, y que serían necesarias a la superación de los métodos utilizados por las escuelas, como los procesos de exposición, que según el propio, solo sirven para "crear profundas antipatías en el alumno"11.

El libro de João Ribeiro sería tan bueno, que aun en las manos del peor maestro, traería buenos resultados al alumno, una vez que "El manual es la carta de navegación por la cual el peor piloto puede llevar el discípulo al porto de destino"12. El libro referido figura frente a la propia escuela y a los programas a los cuales se destina, en función de los colegios brasileños que todavía no estaban aparatados como los europeos, y americanos, con diversos recursos como esculturas, grabaduras, pinturas, entre otros:

11. Araripe Júnior, prefacio de Historia de Brasil, de João Ribeiro, 1900.

12. Ibídem, p. 9.
Es una pena que los programas fatalmente adoptados entre nosotros no hayan permitido que el autor de la historia de Brasil distribuyera los materiales rigorosamente de acuerdo con esa concepción de enseñanza histórica y geográfica. Sin embargo, del examen del libro se ve el empeño utilizado en esta dirección, y esta manifestado el partido que el maestro inteligente puede sacar de los capítulos no destinados a la lectura del alumno. En este punto João Ribeiro abrió, si no me equivoco, una nueva fase para la enseñanza de historia del país, y ojalá que su ejemplo no se quede esterilizado delante de la indiferencia de los que estudian estas cuestiones (página 11).

El manual de Historia de Brasil, por lo que se expuso, sería utilizado tanto por el maestro como por alumno, y era responsabilidad del maestro el direccionamiento por medio de su inteligencia y habilidades, la utilización de mapas, cuadros, articulados a la lectura del libro con los alumnos:

El manual de João Ribeiro constituye un excelente guía en aquel sentido. El alumno tendrá que leer de su libro solo las narraciones y fatos capitales de la historia nacional, lo que puede llamarse de parte dramática de los hechos; lo demás queda a cargo del maestro. El compendio provee todas las indicaciones que deben inducirlo a estudiar (...). Esta dirección en el compendio se le da al preceptor inteligente con criterio deseable, lo que no lo priva de cambiarlo, de acuerdo con la critica que cada maestro haya podido hacer acerca de los documentos originales (página 12). 
En este aspecto, se indicaría el libro como "clave" de enseñanza e iniciación de los maestros, por la magnitud de la calidad de esta obra y del referido autor. Otra cuestión valorada por los autores y editores de libros didácticos era la exposición histórica y la narrativa de los hechos de la historia más cerca del tiempo en que estaban, como un aspecto positivo para algunos, "Otra circunstancia a la que ponemos atención del público es el seguimiento de la exposición histórica hasta nuestros días, hecha por un distinto literato nacional." Una vez que era "una omisión que se observaba en casi todos los compendios de historia patria"13.

Para otros, no habría que contar la historia "reciente", pues:

La parte precisamente relativa a la política interna en el actual reinado al ser y deber ser campo de litigio y de aspiraciones distintas, donde se encontrarán y se combaten todas las aspiraciones y todos los partidos y donde por lo tanto, cada ciudadano es pleiteante interesado y sospecho y no puede ser juez imparcial, pertenece solamente a la alzada del tribunal de la posteridad, que llevará más tarde sus sentencias en el proceso histórico de la actualidad.

João Ribeiro, en Historia de Brasil (Curso superior) termina el libro con la proclamación de la Republica, lo que justifica por su propia “concepción” de historia, una vez que, para él, la glori-

13. Abreu E Lima, Ignácio. Compendio de historia do Brasil. Rio de Janeiro: Laemmert, 1852. Grifos míos. ficación y celebración de los hechos pasados que nos componen es responsabilidad de la historia, en detrimento de las "pasiones del presente": "No crucé la proclamación de la republica (1889); los hechos todavía son actuales y sería prematuro juzgarlos en un libro que se destina al olvido de las pasiones del presente y a la glorificación de nuestra historia".

Rocha Pombo aclara que a través de la lectura de su "librito", aquellos que necesitan "amar a la patria" conocerán mejor "nuestra historia", que es llena de sacrificios y ejemplos de heroísmo, hechos de los cuales debemos enorgullecernos y seguirlos, para caminarnos rumbo al progreso y al desarrollo.

Este sería el "sentido de la historia":

Son esas cosas que fijan nuestra existencia moral. Convirtieron en grande nuestros antepasados. Equivale a volver al compromiso de seguirles en la historia." Este autor utiliza ejemplos de la "actualidad" en sus exposiciones acerca de los hechos "del pasado", al comparar con la vida cotidiana: las mujeres vivían casi cerradas en el interior de las casas, cuidando de los servicios domésticos. Esos servicios eran, entonces, más poderosos que los de hoy. Las mujeres tenían que hacer toda la ropa de la familia. Es verdad que las ropas no eran muchas. Los hombres llevaban solo calzón (o calzoncillos), camisa y, si mucho, chaqueta. Los que podían, e los festivos, llevaban, sobre la chaqueta, o aun de la camisa, un manto. Solo las grandes personas tenían ropas mejores. Las mujeres llevaban faldas cortas y camisas o corpiño. Las faldas eran casi 
siempre dos, una de bayeta y otra de algodón (Pombo, 1917, p. 48).

O aún, acerca de los niños de la época:

Los niños de la época:

Los niños hasta cinco o seis años, caminaban desnudos, y los chicos casi jóvenes, solo llevaban camisón. Pero, si las ropas eran pocas, deberían aun así, costaban mucho hacer a hacer, porque eran hechas a mano. No había máquinas, como hoy, máquinas de coser. Y necesitaban hacer el propio paño, al tejer la lana y el algodón en telares chicos, pues lo poco que venía de Europa era muy caro.

\section{Consideraciones finales}

Para sus autores, la escritura de libros didácticos de historia, y de historia de Brasil, no era un simple ejercicio de erudición. Hacía parte de la dimensión de disputa que hay en esta disciplina, una vez que la historia sería "un campo de litigio". De este modo, las perspectivas de historia de los libros didácticos no son neutrales o imparciales, como defendían muchos, una vez que hasta en la dicha "imparcialidad" hay selección, lo que evidencia y silencia memorias.

En suma, es posible cotejar que a partir de 1870 hubo una progresiva expansión en la enseñanza (pública y privada) y principalmente, la enseñanza para las clases elementares creció significativamente, con una vulgarización del conocimiento histórico vía libros didácticos de historia de Brasil. Tales evidencias de inversiones en libros didácticos se justifican como parte de las luchas y proyectos de reformas en la instrucción "para el pueblo". En este periodo, también se nota en la ciudad de Rio de Janeiro intrínsecamente conectado a la inserción de otros sujetos en las prácticas de cultura letrada en la ciudad. Por eso, este trabajo busca pensar de qué manera el incremento en la oferta de instrucción formal representó una ampliación de los públicos lectores en la ciudad de Rio de Janeiro, al pensar las distintas experiencias alrededor de la educación, edición y difusión de los libros didácticos en Rio de Janeiro entre 1870-1924.

A su vez, en la década de 1920, se pone en evidencia un incremento significativo en el número de habitantes de la ciudad de Rio y la consolidación del declive en el número de analfabetos, más pequeño que la población alfabetizada en la ciudad. Además, en este momento hay una producción de libros didácticos con características distintas de la segunda mitad del siglo XIX, pues hay indicios de un proceso de masificación con un incremento en la cantidad de tirajes de los libros, en la casa de 10.000 ejemplares por edición. La búsqueda por hacer más bajo el precio de la producción y de los libros didácticos se presenta en la estructura grafica volcada hacia los públicos diversos, añadiendo en formato, métodos y renovación del lenguaje por medio de ilustraciones, mapas y otras innovaciones.

Respecto al "público lector" de libros didácticos, es importante reflejar 
acerca de la posibilidad de una ampliación y diversificación del público lector de modo general, lo que extrapola las instituciones de enseñanza oficiales de la época, indicando con esto el desarrollo de distintos modos y usos de la lectura a partir del siglo XIX, concibiendo los libros didácticos más allá del universo escolar, incluyendo los usos hechos por las camadas populares, como alumnos de cursos nocturnos, lectores con autoaprendizaje, como se aprehende en las intenciones de algunos autores y editores de libros didácticos, que buscaban la producción de libros accesibles a la "gente común”. Al acompañar el proceso de masificación del libro didáctico y su articulación con otras redes de comunicación social, se puede comprender como un objeto caro y para consumo de pocos se volvió un producto de "masas", accesible a todos los bolsillos y públicos.

La delimitación de temas, recortes cronológicos, son selecciones de sus autores. Si había quienes se prolongaban en la exposición acerca del emperador Don Pedro II, también había los que hacían largas "biografías de nuestros héroes", o aún, los que terminaban los libros con una lista de la biografía de todos los presidentes de la República.

De este modo, a través del libro didáctico de la historia de Brasil, y de la selección de lo que se diría o no, el olvido y los "usos del pasado" se construían en relación constante con el presente, para legitimarlo o contestarlo. 


\section{Referencias}

Abreu e Lima, I. (1852). Compendio de História do Brasil. Rio de Janeiro: Laemmert.

Araripe Jr, Prefácio. (1900). História do Brasil. Curso Superior. Rio de Janeiro: Francisco Alves, 1900.

Bernardes, M. T. C. C. (1988). Mulheres de ontem? Rio de Janeiro, século XIX. São Paulo: T. A. Queiroz Editor.

Blake, S. (1895). Dicionário Biobibliográfico Brasileiro. Rio de Janeiro: Imprensa Nacional.

Bittencourt, C. (1993). Livro didático e conhecimento histórico: uma história do saber escolar. 1993. Tese (Doutorado). Faculdade de Filosofia, Letras e Ciências Humanas da Universidade de São Paulo, São Paulo.

Bittencourt, C. (2011). Produção didática de História: trajetórias de pesquisas. Revista de História, 164, 487-516.

Cabral, M. V. (1942). Segundo livro de leitura. 15 ed. Rio de Janeiro: Livraria Jacinto.

Chamon, C. S. (2008). Escolas em reforma, saberes em trânsito: a trajetória de Maria Guilhermina Loureiro de Andrade (1869-1913). Belo Horizonte: Autêntica.

Chamon, C. S. (2005). Maria Guilhermina Loureiro de Andrade: a trajetória profissional de uma educadora. 2005. Tese (Doutorado). Faculdade de Educação, Universidade Federal de Minas Gerais, Belo Horizonte.

Coruja, A. (1855). Lições de História do Brasil. Rio de Janeiro: Typografia de M. Gomes Ribeiro.

Coruja, A. (1857). Lições de História do Brasil. Rio de Janeiro: Typografia de M. Gomes Ribeiro, 1857.

Coruja, A. (1873). Lições de História do Brasil. Rio de Janeiro: Tip. Esperança, 1873.

Coruja, A. (1877). Lições de História do Brasil. Rio de Janeiro: Tip. do Figaro, 1877.

Coruja, A. (1854). Aritmética para meninos, contendo unicamente o que é indispensável, e se pode ensinar nas escolas de primeiras letras. Rio de Janeiro: Tip. brasiliense de M. G. Ribeiro, 1854.

Damazio, S. (1996). Retrato social do Rio de Janeiro. Rio de Janeiro: Ed UERJ.

El Far, A. (2004). Páginas de sensação. Literatura popular e pornográfica no Rio de Janeiro (1870-1924). São Paulo: Cia. das Letras.

El Far, A. (2006). O livro e a leitura no Brasil. Rio de Janeiro: J. Zahar. 
Lima da Silva, A. (2019). Libros de texto de la historia de Brasil: Entre sujetos, prácticas y métodos (Río de Janeiro, 1870-1920). Revista Estudios Latinoamericanos, 44-45, 28-53.

Freitas, I. (2007). "História do Brasil para crianças: o livro escolar nos primeiros anos da República e a iniciativa de Joaquim Maria de Lacerda”. Cadernos de História da Educação (UFU), 6, 121-132.

Gasparello, A. (2002). Construtores de identidades: os compêndios de História do Brasil do Colégio Pedro II (1838-1920). Tese de Doutorado em Educação, PUC/SP.

Hallewell, L. (1985). O livro no Brasil (sua história). São Paulo: Ática.

Hansen, P. (2000). Feições e fisionomia: a história do Brasil de João Ribeiro, Rio de Janeiro: Acess.

Lacerda, J. M. (1919). Pequena História do Brasil. Por perguntas e respostas para uso da infância brasileira. Rio de Janeiro: Livraria Francisco Alves.

Lazzari, A. (2004). Entre a grande e a pequena pátria: literatos, identidade gaúcha e nacionalidade (1860-1910). Campinas: Unicamp.

Lima, Y. (1985). A ilustração na produção literária. São Paulo: Instituto de Estudos Brasileiros - USP.

Lucchesi, F. (2004). A história como ideal: reflexões sobre a obra de José Francisco da Rocha Pombo. Dissertação. (Mestrado em Antropologia). Universidade de São Paulo.

Macedo, J. (1095). Lições de História do Brasil para uso das classes primárias. Rio de Janeiro: Garnier.

Mattos, S. (1993). O Brasil em Lições de Joaquim Manuel de Macedo. A história do ensino de história do Brasil através dos manuais de Joaquim Manuel de Macedo. Mestrado (Dissertação em Educação). Fundação Getúlio Vargas, Rio de Janeiro.

Melo, C. (1997). de. Senhores de História: a construção do Brasil em 2 manuais didáticos de história da segunda metade do século XIX. Doutorado em Educação. São Paulo: FAE/USP.

Mello, M. (2007). A república consentida. Cultura democrática e científica no final do império. Rio de Janeiro: Ed FGV; Ed da UFRJ.

Mota, M. A. R. (2000). Sílvio Romero. Dilemas e combates no Brasil da virada do século XX. Rio de Janeiro: FGV.

Peixoto, A. (1916). Minha terra e minha gente. Rio de Janeiro: Francisco Alves, 1916.

Pombo, J.F. R. Nossa pátria. (1917). Narração dos fatos da História do Brasil. Através da sua evolução, com muitas gravuras explicativas. São Paulo: Cia. Melhoramentos.

Pombo, J.F.R. (1948). História do Brasil. São Paulo: Cia Melhoramentos. 
Rio, J. (1987). Mercadores de livros e a leitura das ruas. A alma encantadora das ruas. Rio de Janeiro: Secretaria Municipal de Cultura.

Romero, S. (1890). A história do Brasil ensinada pela biografia de seus heróis. Rio de Janeiro: Francisco Alves.

Romero, S. (1898). Mensagem dos homens de letras do Rio de Janeiro ao Governo Provisório da República do Brasil. Novos estudos de literatura contemporânea. Paris: Garnier.

Teixeira, G. (2008). O grande mestre da escola: os livros de leitura para a escola primária da capital do Império brasileiro. Rio de Janeiro. Dissertação (Mestrado em Educação). UERJ.

Schueler, A. F. (2002). Forma e culturas escolares: práticas, representações e experiências de profissionalização docente em escolas públicas primárias na cidade do Rio de Janeiro (1870-1890). 2002. Tese (Doutorado em Educação). Universidade Federal Fluminense, Niterói.

Silva, A. L. (2008). Ensino e mercado editorial de livros didáticos de História do Brasil -. Rio de Janeiro (1870-1924). Niterói, Dissertação (Mestrado em História). Universidade Federal Fluminense.

Silva, A. L. (2012). Escritas de viagem, escritas da história: estratégias de legitimação de Rocha Pombo no campo intelectual. Rio de Janeiro. Tese (Doutorado em Educação). Universidade do Estado do Rio de Janeiro. 